\title{
Bowel Preparation May Be an Important Adjunct to ERAS in Rectal Surgery
}

\author{
Giuseppe Pappalardo $\cdot$ Saverio Coiro
}

Published online: 23 March 2012

(C) Société Internationale de Chirurgie 2012

We read with great interest the article by Ren et al. [1] on the enhanced recovery after surgery (ERAS) program in radical resection for colorectal cancer. The first point of the ERAS program (fast-track surgery) regards omitting mechanical bowel preparation and oral antibiotic administration. The most extensive reviews cited and the method followed in this article do not differentiate colonic and rectal resections [2-4]. In our opinion there is a significant difference in evaluating the usefulness or not of preoperative bowel preparation in these two different resections. This difference may represents a bias for a correct evaluation of the results without a separate analysis. Moreover, regarding rectal resections, the usefulness of bowel preparation depends on the surgical strategy employed, particularly if a derivative stoma is employed routinely or not. If a derivative stoma is used secondarily only in case of major anastomotic fistulas, as we do [5], the clinical consequences of omitting preoperative bowel preparation may be more serious, with unjustified further risks to the patient. In other words, it is different in case of an early anastomotic fistula to have or not an empty colon and a previous antibiotic administration. We believe that the ERAS method, which offers undoubted advantages even in rectal resections, should be revised in bowel preparation if a primary derivative stoma is not used or selectively employed. Of course more data, obtained by prospective controlled trials, are needed to draw definitive conclusions on this important topic.

\section{References}

1. Ren L, Zhu D, Wei Y et al (2012) Enhanced recovery after surgery (ERAS) program attenuates stress and accelerates recovery in patients after radical resection for colorectal cancer: a prospective randomized controlled trial. World J Surg 36:407-414. doi:10.1007/ s00268-011-1348-4

2. Guenaga KF, Matos D, Castro AA et al (2005) Mechanical bowel preparation for elective colorectal surgery. Cochrane Database Syst Rev 25(1):CD001544

3. Jung B, Påhlman L, Nyström PO et al (2007) Multicentre randomized clinical trial of mechanical bowel preparation in elective colonic resection. Br J Surg 94:689-695

4. Slim K, Vicaut E, Launay-Savary MV et al (2009) Updated systematic review and meta-analysis of randomized clinical trials on the role of mechanical bowel preparation before colorectal surgery. Ann Surg 249:203-209

5. Pappalardo G, Spoletini D, Proposito D et al (2007) Protective stoma in anterior resection of the rectum: when, how and why? Surg Oncol 16(suppl):S105-S108
G. Pappalardo $\cdot$ S. Coiro $(\bowtie)$

Department of General Surgery, Surgical Specialties and Organ

Transplantation "Paride Stefanini", Policlinico Umberto I,

Sapienza University of Rome, Rome, Italy

e-mail: s.coiro@libero.it 